\title{
A Emergência do Acompanhamento Terapêutico e as Políticas de Saúde Mental
}

The emergency of the therapeutic accompaniment and the policy of mental health

Alex Sandro Tavares da Silva \& Rosane Neves da Silva

Universidade de Federal do Rio Grande do Sul

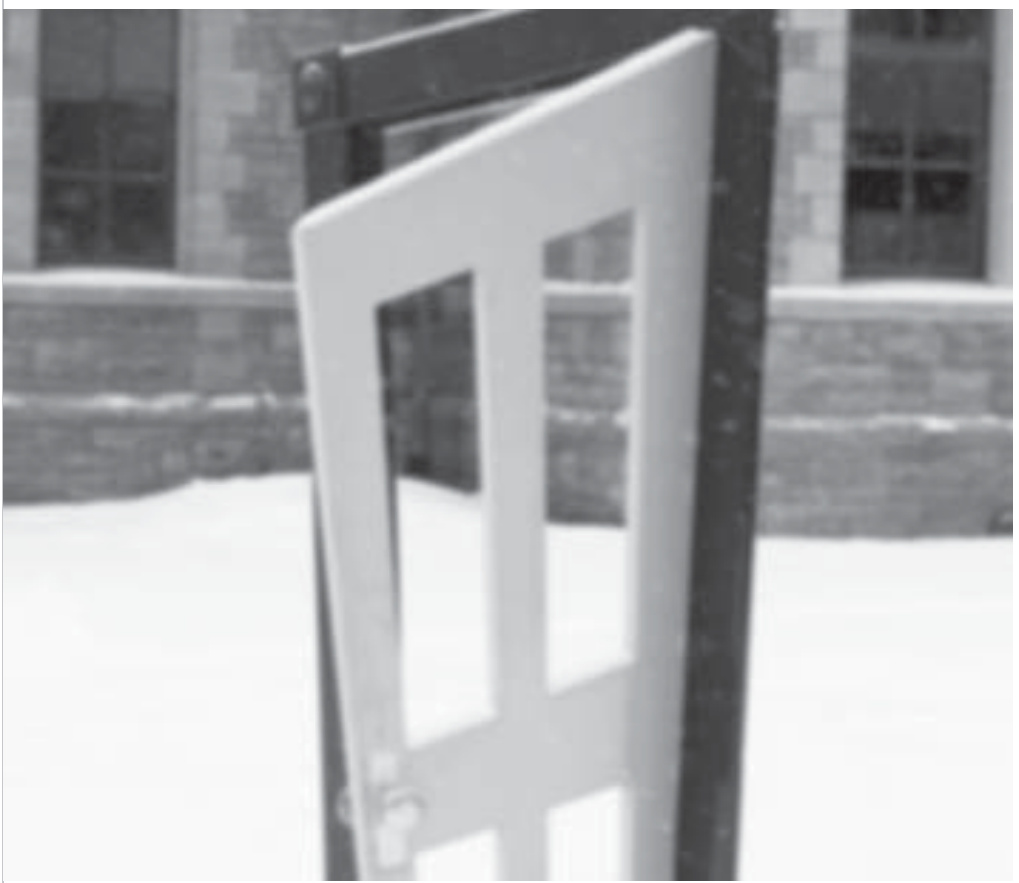




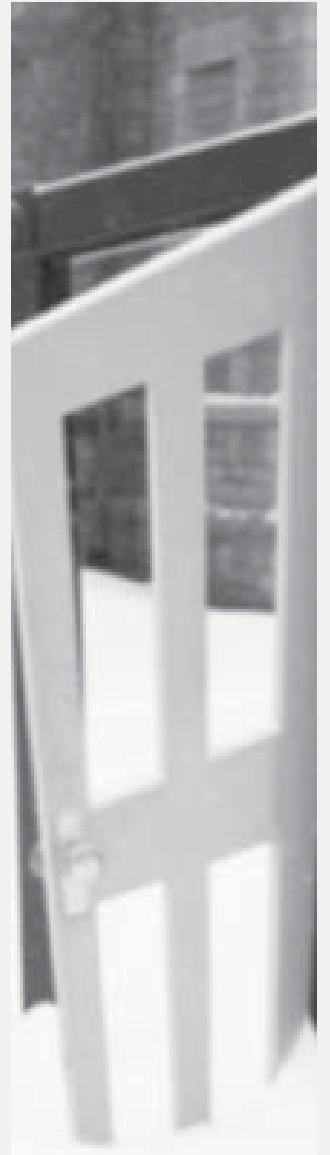

Resumo: Este trabalho visa analisar o processo de emergência do acompanhamento terapêutico (AT). Pretende-se, desse modo, fazer uma viagem crítica pelo mundo das ciências da saúde, tendo como campo de problematização as atividades do AT a partir da segunda metade do século XX. Tradicionalmente, essa prática é pensada em uma "perspectiva integrativa", baseada na idéia de uma "adaptação unidirecional" do paciente. Entendemos, no entanto, que a experiência de conviver com os inusitados encontros que ocorrem nas intervenções do AT produz efeitos que extrapolam as "metas adaptativas", os "protocolos institucionalizantes" e apontam uma dimensão clínica, política e artística da experimentação das relações de força e dos processos de subjetivação aí implicados.

Palavras-chave: clínica, acompanhamento terapêutico, processos de subjetivação.

Abstract: This work targets the analyzis of the emergency process of therapeutic accompaniment (TA). Its objective is, this way, to make a critical journey in the field of health sciences, having the second half of the XXth century as the start point for a field investigation for the TA activities. Traditionally this practice is known as an "integration perspective", based on the idea of a "unidirectional adaptation" of the patient. We understand, however, that the experience that coexists with the unusual situations that occur during the TA interventions produces effects that surpass the "adaptation goals", the "institutionalization protocols", and leads to a clinical, political and artistical dimension in the force relations experimentation and in the subjectivation processes implied in it.

Key - words: clinic, therapeutic accompaniment, subjectivation processes.

As práticas de acompanhamento terapêutico (AT) vêm sendo analisadas principalmente desde a década de 1980. Cada vez mais, percebemos que essa é uma atividade extremamente rica, com um vasto campo de atuação em contínua criação e com uma importante eficácia nos trabalhos que se propõe desenvolver, além de se constituir em um importante campo para pensar a relação entre as práticas em saúde e os processos de subjetivação contemporâneos.

O AT é considerado uma prática na área da saúde que tem como principal característica o fato de ser uma atividade que não fica restrita ao espaço físico de uma determinada instituição - hospital, consultório ou escola, por exemplo. Suas possibilidades de intervenção são tão variadas quanto as suas definições e as histórias que abordam o seu "nascimento". Essa multiplicidade aparece também no modo de problematizar o acompanhamento terapêutico como uma prática no campo da saúde, que pode ser tanto tomado como um programa quanto como uma estratégia de intervenção. Para Edgar Morin (1996), fazer essa distinção entre programa e estratégia é fundamental, pois assinala diferenças que marcam não só os pressupostos teóricos (dimensão epistemológica) quanto as 
... um programa é uma seqüência de atos decididos a priori e que devem começar e funcionar um após o outro, sem variar.

Certamente, um programa funciona muito bem quando as condições

circundantes não se modificame, sobretudo, quando não são

perturbadas. A

estratégia é um

cenário de ação

que se pode

modificar em

função das

informações, dos

acontecimentos,

dos imprevistos

que sobrevenham

no curso da ação.

Dito de outro

modo: a estratégia é a arte de

trabalhar com a incerteza. A estratégia de

pensamento é a

arte de pensar com a incerteza. A estratégia de ação é a arte de atuar na incerteza

Morin escolhas (dimensão ético-estético-política) que orientam a prática. Segundo o autor,

... um programa é uma seqüência de atos decididos a priori e que devem começar e funcionar um após o outro, sem variar. Certamente, um programa funciona muito bem quando as condições circundantes não se modificam e, sobretudo, quando não são perturbadas. A estratégia é um cenário de ação que se pode modificar em função das informações, dos acontecimentos, dos imprevistos que sobrevenham no curso da ação. Dito de outro modo: a estratégia é a arte de trabalhar com a incerteza. A estratégia de pensamento é a arte de pensar com a incerteza. A estratégia de ação é a arte de atuar na incerteza (Morin, 1996, p. 284).

Nessa perspectiva, o AT pode ser pensado como uma estratégia de pesquisa-intervenção que vai sendo construída a partir de experimentações, numa aposta ético-estética de análise dos movimentos inéditos da/na vida, ainda que, muitas vezes, seja tomado como um programa de adaptação, que segue passos (pré)determinados para alterar "comportamentos de loucos".

Nosso objetivo é mostrar que a constituição do acompanhamento terapêutico, como prática no campo da saúde, é marcada inicialmente por essa lógica do programa caracterizada por demarcar funções, lugares e hierarquias no trabalho terapêutico -, mas aponta, ao mesmo tempo, a necessidade de se pensar essa prática como uma estratégia de produção de novos sentidos.

\section{O contexto \\ histórico e a emergência do acompanhamento terapêutico}

De maneira geral, as produções teóricas acerca do AT relacionam sua função e processo de constituição a um movimento mais amplo de crítica às intervenções pautadas pela lógica psiquiátrica clássica, fundamentalmente àquelas que estavam em vigor até a década de 1950, principalmente na Europa e EUA. O surgimento do hospital-dia, dos psicofármacos, da comunidade terapêutica, assim como as questões suscitadas pela reforma psiquiátrica, possibilitaram a invenção de uma prática que, com o passar do tempo, passou a ser denominada acompanhamento terapêutico. Nesse sentido, podemos dizer que essa prática está diretamente vinculada à necessidade de criação de novos métodos de atenção intensiva de cuidado à saúde que vão configurando-se a partir da segunda metade do século XX. É no contexto de uma certa "urgência sanitária" que podemos entender a criação do hospital-dia e das comunidades terapêuticas e situar o papel que a própria produção de psicofármacos desempenhou naquele momento. É nesse contexto - onde está ocorrendo uma mudança significativa na perspectiva de cuidado aos doentes, se comparada com as práticas usadas nos clássicos manicômios - que vão se engendrar as condições para que a prática do AT possa desenvolver-se no campo da saúde. Com o surgimento do hospital-dia, no pósguerra, assistimos à criação de um espaço terapêutico onde os pacientes realizam determinadas atividades que são finalizadas à noite, momento no qual retornam as suas comunidades. O primeiro hospital-dia foi criado em 1946, por Ewen Cameron, no "Allan Memorial Institute", em Montreal, Canadá (Campbell, 1986). No início, por ainda não existirem as "drogas mentais" para "conter os loucos", esse espaço era dedicado aos sujeitos que possuíam determinadas patologias que não ofereciam perigo para as outras pessoas nem para si mesmos.

No final da década de 1940 e início de 50, com a invenção de substâncias que prometiam alterar o funcionamento neuropsicológico do sujeito tido como louco, essa "triagem" que definia os pacientes que poderiam participar das atividades do hospital-dia passou a ampliarse consideravelmente. Em 1949, aconteceu a avaliação da primeira "droga mental", quando o terapeuta australiano John F. Cade comprovou 
que o carbonato de lítio controlava o humor do "doente bipolar", rotulado, naquela época, de "psicótico maníaco-depressivo". Essa nova intervenção ficou potencializada em 1952, quando, na França, os pesquisadores Jean Delay e Pierre Deniker utilizaram e testaram o neuroléptico clorpromazina. Assim, essa droga acabou constituindo-se em uma das primeiras "armas" no tratamento químico dos transtornos psicológicos e inaugurou a psicofarmacologia.

A invenção dos psicofármacos apontou um novo rumo no tratamento dos "transtornos mentais". Nesse processo, ocorreu a gradual e progressiva substituição da camisa-de-força pelo controle químico do comportamento tido como desviante. Juan Carlos Stagnaro, em entrevista a Pulice e Rossi (1997, p.83), afirma que o acompanhamento terapêutico surgiu numa época de maior "difusão da psicofarmacologia", que permitiu tanto a experiência dos serviços abertos quanto a "circulação dos psicóticos" pela cidade e sua possível "reinserção social". Se, por um lado, esse tipo de remédio fez com que os "pacientes perturbados" conseguissem mudar condutas e executar determinadas atividades socialmente aceitas, por outro, assinalou uma mudança importante nas técnicas de subjetivação. Antes, a técnica tinha um caráter disciplinar, com programas de "cuidado" mecânicos e visíveis (contenção física, amarras na cama, camisa-de-força, pancadas na cabeça, eletrochoques, hidroterapia, cirurgias cerebrais, etc.); com o advento dos psicotrópicos, deu-se a passagem da "terapêutica disciplinar" para a "terapêutica do controle" químico e invisível, ou seja, o sujeito tomado por louco, doente e perigoso "consegue sair" da estrutura manicomial desde que leve consigo, no mínimo, o suporte químico dessas mesmas estruturas, representado pelos psicofármacos, e seja acompanhado nessa circulação por um "agente terapêutico", o acompanhante, o auxiliar, o atendente. Portanto, não é à toa que uma das primeiras funções dos acompanhantes terapêuticos foi o controle da ingestão dos remédios prescritos e a vigilância do comportamento fora da instituição manicomial. Através do uso da medicação e da "companhia especializada", os "internados" começam um processo de errância (controlada física e quimicamente) pelo espaço urbano.

Com o crescente uso de agentes (enfermeiros, terapeutas ocupacionais, auxiliares) e remédios, começam a pulular, ainda na primeira metade da década de 1950, outros meios de cuidar no âmbito da saúde mental. É nesse contexto, por exemplo, que surgem as comunidades terapêuticas $(\mathbf{C T})$.

Julio Moizeszowicz, em entrevista a Pulice e Rossi (1997), diz que o modelo conceitual do acompanhamento terapêutico está baseado na comunidade terapêutica diurna. Esse termo foi criado pelo inglês Maxwell Jones, que dirigia uma instituição na Escócia, em 1952, chamada "Hospital de Dingleton". Essa proposta foi utilizada, pela primeira vez, em excombatentes da Segunda Guerra Mundial.

Jones dizia tentar estabelecer a quebra da hierarquia entre os profissionais da saúde e os pacientes (controlados com remédios), além de criar um "ambiente humanizado" dentro da instituição, ou seja, com os argumentos de Jones (1968), encontramos o suporte para a construção da $\mathbf{C T}$, cujos objetivos poderiam ser definidos como: 1. Promover uma "interação bidirecional", fazendo-se necessária uma crítica à idéia de que o técnico é o único que tem o saber em oposição ao doente, o "alienado"; 2. Buscar a "implicação dos técnicos", que são convidados a repensar suas práticas de intervenção cotidianas, questionando, assim, a separação entre quem trata e aquele que é tratado; 3 . Investir no trabalho de grupo, de pacientes e/ou de técnicos, tentando romper o modelo hierarquizado dos antigos hospitais psiquiátricos; 4. Trabalhar a idéia de "cultura terapêutica", a fim de proporcionar o "ambiente adequado" para que a 
"aprendizagem social" se efetive com todos os membros da comunidade.

A CT de Jones, apesar de ainda ser pautada por uma lógica adaptativa, produz uma crítica importante ao funcionamento do "clássico manicômio", pois coloca em evidência os "efeitos terapêuticos" que advêm da implicação dos agentes nas relações sociais da comunidade. Apesar de tais alterações, a comunidade terapêutica ainda mantém o mesmo raciocínio asilar, uma vez que os pacientes ainda ficavam dentro da instituição (medicados, talvez dopados), só que agora de uma forma mais "democrática" e "adornada". A maioria das produções que se debruçam sobre a crítica às estruturas manicomiais coloca o italiano Franco Basaglia, mais que o inglês Maxwell Jones, como quem levou mais longe os questionamentos político/sociais à psiquiatria, configurando, assim, a "Psiquiatria

"[...] não eram apenas os pacientes que se asfixiavam nessa paisagem [manicomial], mas também os profissionais que nela atuavam" Alternativa" ou a "Psiquiatria Democrática". Basaglia (1982, p. 85) irá criticar o modelo inglês de $\mathbf{C T}$ dizendo que o mesmo é apenas "uma reciclagem da velha gestão manicomial": o grande risco dessas "comunidades" seria o de fecharem-se sobre si mesmas e continuarem funcionando na antiga "lógica manicomial".

Paralelamente a esses movimentos alternativos, os programas de controle, característicos da estrutura manicomial, começam a entrar em processo de falência, pois não conseguem dar conta do que prometiam, ou não forneciam o que vendiam: o paciente continuava sendo visto como o louco doente, apesar da medicação (psicofármacos), que continuava mantendo as mesmas relações de poder dentro da estrutura hospitalar.

O desejo de destruir as estruturas manicomiais torna-se mais visível na década de 1960 (Guattari, 1992). Nesse momento, as experiências criadas na comunidade terapêutica de Gorizia (Itália) são tidas como fundamentais. Nessa instituição, Basaglia tenta humanizar o "sistema de saúde mental" no espaço intramuros, mas descobre que essa meta é inacessível, pois ainda é pautada pela "lógica manicomial", do confinamento e da produção de doença. Desse modo, a partir de 1963, os italianos passam a abrir as portas de Gorizia e criar outras formas de lidar com a questão da saúde, principalmente mental (Leonardis; Mauri; Rotelli, 1990).

Nessa época, o mal-estar do/no trabalho manicomial passou a generalizar-se em vários países (Itália, França, EUA, Brasil, Argentina). Muitos profissionais começaram a manifestar o seu desconforto, alguns inclusive adoecendo, com as "atividades terapêuticas" realizadas nesses locais. Como escreve Rolnik (1997, p. 83): “[...] não eram apenas os pacientes que se asfixiavam nessa paisagem [manicomial], mas também os profissionais que nela atuavam". Nesse "campo de batalha", também os usuários dos serviços começaram a manifestar o que vinham passando dentro dos manicômios, mostrando o seu ponto de vista sobre os "aparatos terapêuticos" aos quais estavam submetidos. Com isso, esses "locais de tratamento" passam a ser vistos como lugares de manutenção e/ou promoção da doença, não só dos pacientes.

O uso de agentes que não ficavam atuando apenas dentro do hospital, e que ainda não tinham sido batizados de "acompanhantes terapêuticos", começou a ficar potencializado, juntamente às novas experiências que estavam sendo gestadas no campo da saúde mental. A prática das atividades terapêuticas dentro do hospital e também fora das comunidades terapêuticas ganhou um novo impulso a partir das propostas da reforma psiquiátrica que teve início em alguns países da Europa. Félix Guattari (1992) escreveu sobre as suas experiências institucionais ainda na década de 1950, na Clínica de La Borde, na França, o mesmo acontecendo com Franco Basaglia (1982), no início da década de 1960 e, principalmente, na década 1970, na Itália. Inúmeras reflexões, manifestações e eventos criaram o contexto 
para que a reforma psiquiátrica assumisse um caráter legislativo e fosse aprovada em 13 de maio de 1978, na Itália, a "Lei 180", que passou a proibir a internação em manicômios. Essa lei decretou também a progressiva desocupação dos antigos manicômios e a criação de outras estruturas que pudessem dar conta da desinstitucionalização da loucura. Nesse contexto de eliminação das estruturas manicomiais, surgem alguns "operadores" que se lançavam com os internados no tecido urbano, não tendo uma instituição de referência (Leonardis; Mauri; Rotelli, 1990).

Há, portanto, vários autores que vinculam a emergência do $\mathbf{A T}$ a esse movimento de crítica às estruturas manicomiais, expressos tanto pela reforma psiquiátrica quanto pelo movimento antimanicomial (Rolnik, 1997). Essa aproximação torna-se possível porque o acompanhamento terapêutico, ao promover a circulação pelo espaço urbano de sujeitos que, até então, estavam enclausurados dentro dos manicômios, acaba apostando na produção de novos modos de subjetivação a partir desse encontro das diferenças.

Impulsionadas pelas críticas institucionais e experiências mundiais de progressivo desmonte das estruturas manicomiais, nos anos 80, as práticas em psiquiatria, também no Brasil, começam a ser objeto de vários tipos de análise e denúncias. Porém, antes disso, tivemos, ao contrário, um grande investimento no modelo manicomial. No Brasil, principalmente a partir do golpe militar de 1964, ocorreu um forte desinvestimento, por parte do governo federal, na "saúde pública". A nova estratégia era ampliar a construção das clínicas psiquiátricas, beneficiando fundamentalmente o setor privado, que contava com o suporte econômico da "previdência oficial". Conforme Ferreira (2003, p. 176), no ano de 1978, o INAMPS (Instituto Nacional da Previdência Social) gastava 95\% da sua verba com a manutenção das práticas em "saúde mental", sustentando 269 hospitais da "rede privada".
Como escreve Coimbra (1995, p. 55), "a década de 60 , no Brasil e no mundo, pode ser caracterizada como os anos instituintes, quando pensávamos mudar o mundo, quando nossos sonhos e utopias seriam realizados". Essas manifestações generalizadas contra a massificação subjetiva inerente ao modelo manicomial deram início aos primeiros movimentos para uma reforma psiquiátrica brasileira. Segundo a autora, algumas práticas "psi", principalmente na virada da década de 60 para 1970, entraram num processo de repensar as suas atividades terapêuticas. Nesse contexto, surgem reflexões que conduzem à análise da "implicação política" dos profissionais que trabalham na área "psi". A subjetividade passa a ser pensada "enquanto produção histórico-social" e, além disso, surgem reflexões sobre "[...] os efeitos que nossas práticas, nossos modelos e saberes estão produzindo / reproduzindo e fortalecendo no mundo" (Coimbra, 1995, p. 60).

Com o recrudescimento da ditadura militar no final dos anos 60 e até praticamente o início dos 80 , assistimos a uma brusca interrupção nesse movimento de crítica ao modelo manicomial, havendo um implemento da lógica asilar com a proliferação de novos hospitais psiquiátricos. Somente no final dos anos 80, com a consolidação do processo de abertura política no País, foram retomadas as discussões em torno da reforma psiquiátrica. Em 1986, ocorreu no Brasil a "8” Conferência Nacional de Saúde", criando as novas diretrizes do sistema único de saúde (SUS), que seria pautado pela universalidade, integralidade e democratização da saúde. Muitos autores consideram que esse foi o começo do processo que culminou com a reforma psiquiátrica brasileira. No final da década de 1980, no "II Congresso Nacional dos Trabalhadores de Saúde Mental", configurou-se o campo de forças que possibilitou a criação do "Movimento da Luta Antimanicomial", congregando inúmeros profissionais da área da saúde, principalmente mental, além de usuários desses serviços e seus familiares. Esse 
"Se fôssemos fazer uma genealogia do acompanhamento terapêutico, seria importante

identificar algumas das forças que conduziram à invenção dessa prática no campo da saúde: a produção dos psicofármacos no final da década de 1940; a experiência do hospital-dia e das comunidades terapêuticas a partir dos anos 50 e o início das discussões em torno da reforma psiquiátrica que culminam com a criação do Movimento de Luta Antimanicomial. movimento caracteriza-se por ser regido pelos próprios usuários dos serviços em saúde mental, que colocam em xeque as "intervenções terapêuticas" às quais são submetidos, tendo como foco de problematização o exercício constante de luta contra toda e qualquer forma de opressão e massificação subjetiva. O movimento produz, assim, forças fundamentais que transformam não só a imagem que se tem dos usuários mas também os próprios saberes e práticas daqueles que trabalham com os mesmos.

Em 1989, após 11 anos da Lei italiana, surgiu no Brasil o projeto de Lei no 3657/89, que trata da "Lei da Reforma Psiquiátrica". Em 1992, na "Il Conferência Nacional de Saúde Mental", foi declarado um dever "efetuar a desinstitucionalização de todas as instituições com características manicomiais". Nesse momento, foi aprovada a criação de uma "Rede de Atenção Integral em Saúde Mental" em substituição ao Hospital Psiquiátrico. No dia 07 de agosto de 1992, foi aprovada a Lei Estadual no 9.716, que dispõe sobre a reforma psiquiátrica no Rio Grande do Sul. Finalmente, em 06 de abril de 2001, ocorreu a aprovação da Lei Federal no 10.216, da reforma psiquiátrica brasileira, que estabelece uma diretriz não asilar para o financiamento público e o ordenamento jurídico da assistência psiquiátrica no País. Contudo, o processo da reforma psiquiátrica não acaba com a criação dessa Lei Federal, pois a vontade de retomar a lógica manicomial está sempre presente, inclusive no funcionamento das entidades médicas (Simers, 2005). É preciso que esse movimento se espalhe por todo o tecido social com a implicação de vários setores da sociedade.

Nessa relação de forças e de questionamento da estrutura manicomial, a prática do AT também terá que ser re-significada de outro modo. Vimos que, desde meados do século XX, há um campo possível para a emergência do acompanhamento terapêutico como uma prática associada ao campo da saúde mental. No entanto, já no início do século XX, encontraremos a descrição de alguns trabalhos isolados que continham, de forma embrionária, os pressupostos do que viria a configurar a prática do AT. Carvalho (2004) menciona o trabalho do terapeuta francês Eugene Minkowsky, que viveu durante dois meses na casa do seu paciente. "De certo modo, Minkowsky atuou como hoje o fazem os acompanhantes terapêuticos em situações de acompanhamento de tempo integral" (Carvalho, 2004, pp. 2829). Alguns autores (Antonucci, 1994, e Carvalho, 2004) citam a experiência de um "acompanhamento terapêutico" realizado por uma "enfermeira psiquiátrica" na Suíça, no ano de 1937. Essa enfermeira teria sido treinada por uma psicoterapeuta, Mme. Sechehaye, para dar assistência à paciente Renée, que estava em análise e "internada" na casa dessa psicanalista. Nesse caso, o "AT" foi uma prática utilizada para sustentar a continuidade de um tratamento psicológico, mesmo quando a psicoterapeuta estava ausente.

Se fôssemos fazer uma genealogia do acompanhamento terapêutico, seria importante identificar algumas das forças que conduziram à invenção dessa prática no campo da saúde: a produção dos psicofármacos no final da década de 1940; a experiência do hospital-dia e das comunidades terapêuticas a partir dos anos 50 e o início das discussões em torno da reforma psiquiátrica que culminam com a criação do Movimento de Luta Antimanicomial.

O que fica evidente nesse percurso é que, na constituição do seu campo, o acompanhamento terapêutico mostrava-se como um recurso auxiliar para pacientes graves, alguns considerados "crônicos", que ia de encontro a uma lógica que desejava deixar a pessoa que é rotulada de louca apenas dentro dos hospitais psiquiátricos. Assim, desde sua configuração inicial, o AT mostra essa ruptura com o "modelo tradicional de saúde mental", que buscava isolar o paciente dentro do hospício e controlar todas as manifestações tidas como anormais. 


\section{A experiência do acompanhamento terapêutico no Brasil}

Analisaremos agora o campo de emergência do acompanhamento terapêutico no Brasil, com um foco inicial na cidade gaúcha de Porto Alegre. Segundo a fala de Luiz Cezar de Oliveira Inem (apud Bustamante, 2003), em Porto Alegre, teria ocorrido a "experiência pioneira" de AT no Brasil.

Tomando como base algumas entrevistas com sujeitos que participaram dessa experiência e a análise das produções teóricas sobre a constituição do AT disponíveis até o momento, podemos dizer que a configuração dessa prática na Clínica Pinel (ou "Associação Encarnación Blaya - Clínica Pinel") em Porto Alegre inaugura o campo do acompanhamento terapêutico no sul do Brasil. Essa instituição foi criada em 1960 por Marcelo Blaya, após o mesmo ter finalizado sua formação nos EUA. Desde o início do seu funcionamento institucional, eram oferecidos serviços considerados "inovadores", tais como: socioterapia, grupos operativos, ambientoterapia, reuniões comunitárias, além de ocorrer a implicação e o reconhecimento das atividades desenvolvidas pelos psicólogos e assistentes sociais nas equipes de trabalho. Como parte desses "novos serviços", incluíase a prática de um agente específico, que, nesse momento, tinha o nome de "atendente psiquiátrico". A inclusão desses "atendentes" na equipe foi proposta por Blaya, que, durante a sua formação, teria ficado interessado no trabalho desenvolvido por esses agentes que andavam com os "loucos" pelas ruas americanas.

O "atendente" era um agente auxiliar que trabalharia no sentido de colocar em ação os programas de tratamento elaborados pelo psicoterapeuta, fazendo com que os pacientes aprendessem determinadas condutas que deveriam ser executadas tanto dentro da $\mathbf{C T}$ como fora dali. O "atendente psiquiátrico" seria um agente integrador, que circulava como um "atendente grude" pelo tecido urbano. A expressão "atendente grude" era utilizada pelos psicólogos e médicos da Pinel para falar da função do "atendente psiquiátrico". "Grudar" para evitar que o inusitado se faça presente; impedir que o paciente morra, mate ou agrida. Assim, o "grude" era utilizado para situações de risco de suicídio e/ou de agressão. Nesse sentido, ou o paciente ficava contido mecanicamente ou ficava com o acompanhante.

Dentro da Clínica Pinel, os pacientes tinham uma série de atividades (pré)montadas, com hora marcada (grupos operativos, lazer, praxiterapia, alimentação, higiene, terapia, etc.) e o "atendente psiquiátrico" era um pólo central através do qual, pelo vínculo estabelecido, os internos iam progressivamente sendo encaminhados até as atividades. $\mathrm{O}$ "atendente" era uma referência fundamental para sustentar essa concepção de $\mathbf{C T}$, e sua função consistia basicamente em direcionar os pacientes para que os mesmos executassem a programação institucional de mudança de comportamento.

Nessa época, no exercício da função de "atendente psiquiátrico" havia, em sua grande maioria, estudantes de Psicologia e Medicina, os quais, com a prática do acompanhamento terapêutico, cumpriam uma parte da sua formação clínica - "estágio supervisionado", ou ainda alguns sujeitos sem formação de nível superior que ficavam sabendo, através de um anúncio de jornal, que existia mais uma atividade remunerada na área da saúde: a de "atendente psiquiátrico".

Segundo a fala de um "atendente psiquiátrico leigo", sem formação médica ou psicológica (citado por Reis Neto, 1995), o trabalho na Pinel era sempre focalizado na circulação pela rua, tentando "descaracterizar essa 'coisa' psiquiátrica"; esses agentes tentavam "não fazer do paciente um paciente, mas uma 
pessoa". Esse "acompanhante leigo" comenta que trabalhava apenas com a "parte sadia" do paciente, pois, aos atendentes, era vedado "trabalhar com a doença". Desse modo, tinham apenas uma "conduta de contenção".

Através dessas manifestações, é possível identificarmos três aspectos presentes na constituição inicial dessa prática: o primeiro estaria relacionado à necessidade de criação de um "meio saudável"; o segundo, a uma perspectiva de promoção de saúde, ao invés de uma ênfase exclusiva no tratamento do patológico, e o terceiro, à intenção de criar uma relação de poder específica, na qual, de um lado, encontra-se o psicoterapeuta (que cura) e, de outro, o seu auxiliar (que ajuda no cumprimento de determinadas diretrizes clínicas). Assim, o "atendente psiquiátrico" seguiria as ordens de "grudar no paciente" para que o psicoterapeuta fizesse a intervenção que de fato promoveria a saúde do mesmo.

Conforme Reis Neto (1995), o que era exigido desse atendente seria "[...] mais próximo ao saber do 'homem das ruas', balizado pelas diretrizes mais objetivas que lhe serão fornecidas no interior da própria clínica". E mais, segundo esse psicólogo, uma das experiências que poderia ter servido como inspiração para a criação do "atendente psiquiátrico" seria aquela em que eram chamadas as pessoas da própria comunidade extra-hospitalar para servirem como "elos na reintegração" do paciente. Nesses casos, o importante não era a "cultura acadêmica" (teórica e técnica), mas a necessidade de abordar a "doença mental" de uma perspectiva "político-social". Desse modo, o "atendente" seria o "homem da rua" incorporado à equipe terapêutica.

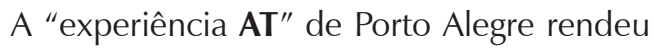
alguns "frutos" e produziu "férteis sementes", como as que "brotaram" no Rio de Janeiro, em novembro de 1969, quando iniciaram os trabalhos da Clínica Villa Pinheiros. A experiência carioca atribuiu um novo nome e acabou tomando um referencial teórico distinto para demarcar essa prática: tratava-se agora do "auxiliar psiquiátrico", com uma influência mais para o lado da psicanálise do que propriamente dos pressupostos teóricos da comunidade terapêutica americana.

Podemos dizer que, desde o início da década de 1960, a prática e a teorização no/do acompanhamento terapêutico vêm gradualmente crescendo, ocupando novos espaços. Por exemplo, hoje, no Rio Grande do Sul, temos o trabalho do AT em vários pontos da rede de serviços da área da saúde, não só no "setor privado" mas também no "setor público": "[...] de um recurso para intervenção na área da psicopatologia ele passa a ser, também, dispositivo complementar ou substitutivo para trabalhar com serviços de saúde pública" (Pelliccioli; Guareschi; Bernardes, 2004). Com isso, vem crescendo a oferta de ensino do acompanhamento terapêutico nas clínicas privadas, universidades (em nível de extensão), além de experiências importantes de "qualificação" destinadas aos servidores da rede pública na área da saúde mental.

Para se ter uma idéia de uma experiência de capacitação de trabalhadores de saúde mental que ocorreu entre 1999 e 2002, basta mencionar o curso oferecido pela Escola de Saúde Pública do Rio Grande do Sul. Esse curso foi direcionado a trabalhadores de nível médio, sem formação universitária, da rede pública. Chamava-se "Curso Básico de Qualificação em Acompanhamento Terapêutico", tinha a duração de oito meses e ocorreram, no total, três edições. A última edição finalizou em janeiro de 2003 (Palombini, 2003 e 2004). Esse curso pode ser considerado um marco importante para pensar a prática dos trabalhadores da área da saúde, remetendo a uma discussão que envolve outras ações de cuidado, e, principalmente, para problematizar o AT como uma estratégia de produção de novos sentidos e não como um programa que visa à "profissão" de um "agente 
independente" e "formado" em acompanhamento terapêutico.

Atualmente, o acompanhamento terapêutico em Porto Alegre e em outras cidades brasileiras está sendo pensado para além de uma prática de tratamento de "doentes mentais", contando, inclusive, com várias produções acadêmicas que falam da sua clínica e das intervenções em outros contextos, alguns considerados ainda inusitados, como, por exemplo, o cinema (Sereno, 1997). O campo do AT está, portanto, em crescente expansão, e seu futuro é imprevisível, pelo menos aqui no Brasil, onde essa estratégia é amplamente usada e constantemente recriada. Com diz Chnaiderman (2004, p. 14), “[...] o acompanhamento terapêutico questiona o mundo contemporâneo ao propor formas inusitadas de ocupação do espaço urbano".

\section{A prática do acompanhamento terapêutico: programa de adaptação ou estratégia clínica?}

Após termos mapeado alguns elementos do contexto histórico da "experiência AT", gostaríamos de retomar as idéias de Morin (1996) sobre a diferença entre as noções de programa e estratégia para fazer algumas considerações sobre a prática do AT. Vimos que, apesar de essa prática constituir-se a partir de uma crítica ao modelo manicomial, ela acabava reproduzindo uma lógica adaptativa que não fazia nada mais do que transferir o programa de controle sobre o paciente para além dos muros da instituição psiquiátrica. $\mathrm{O}$ acompanhante terapêutico, na maioria das vezes, ficaria restrito a uma atividade voltada para a adaptação do paciente, tendo uma função de contenção e seguindo diretrizes claras e predeterminadas. Ele funcionaria meramente como um auxiliar da equipe responsável pelo tratamento do paciente: sua função era ir ao encontro do paciente para ver o que estaria errado no seu cotidiano e voltar com essas "informações fidedignas"
(Mauer; Resnizky, 1987) para serem compartilhadas com uma equipe que definiria o que deveria ou não ser feito fora da instituição. Portanto, o "auxiliar" vai à rua para registrar comportamentos e emoções do paciente e fazer "anotações da realidade": trata-se de um escriturário assistencial. Nesse sentido, o foco de trabalho fica canalizado na mudança do funcionamento anormal do doente. Busca-se tratar o patológico do paciente e de sua família com o uso das informações do AT. Em suma, o problema estaria no acompanhado e/ou em sua família. O acompanhante terapêutico seria alguém que representaria a instituição fora da instituição, um agente que coleta informações fidedignas e que levaria para rua, escola, casa do paciente, etc. os conhecimentos (saberes e técnicas) que seriam "pensados" dentro da instituição. Para problematizar o acompanhamento terapêutico como uma estratégia clínica, é preciso considerar o grau de abertura à criação de intervenções que está constantemente atravessando e constituindo essa prática. $\mathrm{O}$ agente, nesse caso, pode, inclusive, interpretar. Como escrevem Porto e Sereno (1991, p. 29), o “[...] acompanhante interpreta o sujeito nos momentos em que a concretização da montagem da cena se interrompe e exige sua intervenção através de ações".

A prática do AT, nesse caso, acaba tomando a rua como "dispositivo clínico": nos diferentes percursos pela cidade, muito mais do que se orientar ou ambientar-se, trata-se de usar o próprio tecido urbano como espaço de novas produções de sentido, fazendo com que as próprias intervenções desse espaço possam adquirir uma função terapêutica.

Podemos dizer que os acompanhamentos terapêuticos constituíram-se a partir dessa vontade de acompanhar o sujeito, com circulação ainda restrita, pelo tecido urbano, ou seja, o agente buscava circular com o acompanhado que estava isolado do convívio social e submetido a uma rede de saberes, principalmente da área da saúde mental. 
É este o nosso grande desafio: perceber que nossas práticas são datadas

historicamente, que estamos produzindo cotidianamente perplexidadese incoerências, mas que, através de nossas implicações com os diferentes movimentos sociais que se espalham pelo mundo, podemos criar novos dispositivos de intervenção, novos espaços, novos saberes e novos sujeitos.
Apesar de o AT ter se configurado inicialmente como uma prática integrativa que buscava apenas adaptar os loucos ao funcionamento tido como "natural" e "normal" da sociedade de consumo, com o passar do tempo, suas intervenções e teorizações passaram a apontar outras estratégias de ação, criando, em conseqüência, novas funções para essa prática.

Destacamos, a seguir, alguns territórios dessas novas funções do AT, indicando as suas fontes bibliográficas: 1. Na terapêutica para famílias (Teixeira; Dename; Balduino, 1991); 2. Na produção de documentários, filmes e curtametragens (Sereno, 1997); 3. Em intervenções clínicas e reflexões éticas (Barretto, 1998); 4. Na constituição de "repúblicas" e casas de passagem (Cauchick, 2001); 5. Na implicação da escola na inclusão de alunos (Gavioli; Ranoya; Abbamonte, 2001); 6. Na inclusão de jovens que praticaram delitos (Almeida et al., 2003); 7. Na crítica às mídias e criação de sentidos do/no espaço urbano (Silva, 2003); 8. Em intervenções de "cunho social" (Pelliccioli; Guareschi; Bernardes, 2004); 9. Como dispositivo da reforma psiquiátrica (Cabral; Belloc, 2004); 10. Na criação de novos encontros entre instituições de saúde e usuários (Palombini, 2004).

Ao apresentarmos esses novos territórios do AT, procuramos mostrar que suas intervenções e estratégias são "andarilhas", sendo fundamental que continuem assim. Desse modo, deparamo- nos com a criação constante de modos inusitados de fazer acompanhamentos terapêuticos, que não devem permanecer limitados ao seu caráter integrativo, mas suscitar a dimensão clínica, política e ético-estética que se produz nessa composição de forças que atravessam e constituem esse dispositivo AT.

Desse modo, fica evidente a necessidade da constante problematização das práticas desses profissionais que agem como acompanhantes terapêuticos. Essa problematização deve, sem dúvida, levar em consideração o jogo de forças que marca a constituição dessa prática e do quanto o próprio agente produz essa prática a todo momento, viabilizando, assim, a criação de novas produções de sentido na experiência de todos aqueles aí implicados: não só do acompanhado mas também do acompanhante e dos demais participantes que acabam partilhando dessa "experiência andarilha" pela cidade.

É este o nosso grande desafio: perceber que nossas práticas são datadas historicamente, que estamos produzindo cotidianamente perplexidades e incoerências, mas que, através de nossas implicações com os diferentes movimentos sociais que se espalham pelo mundo, podemos criar novos dispositivos de intervenção, novos espaços, novos saberes e novos sujeitos. Esse desafio está colocado, e muitas práticas, em seus microespaços, tentam avançar e, efetivamente, estão conseguindo produzir territórios onde a crítica, o questionamento, a criatividade, a multiplicidade se encontram presentes (Coimbra, 1995, p. 61).

\section{Alex Sandro Tavares da Silva}

Psicólogo, psicoterapeuta, Mestre em Psicologia Social e Institucional (UFRGS). Editor do "Site AT": http://siteat.cjb.net/.E-mail: alextavares@pop.com.br

\section{Rosane Neves da Silva}

Psicóloga, professora do Programa de Pós-Graduação em Psicologia Social e Institucional (UFRGS). E-mail: rosane.neves@ufrgs.br

Rua: Chico Pedro, no 206, apto 206. Bairro: Camaquã. Porto Alegre, RS, Brasil. CEP: 91910-650.

Recebido 25/05/05 Reformulado 01/03/06 Aprovado 24/03/06 
ALMEIDA, M. M. et al. A Prática do Acompanhamento Terapêutico com Jovens Autores de Delito. Primeiro Congresso Ibero-americano de Acompanhamento Terapêutico. Faculdade de Medicina, Universidade Nacional de Buenos Aires-Buenos Aires, 2003.

ANTONUCCI, R. Terapias Ressocializantes: o Acompanhante Terapêutico. In Assumpção Jr., F.B. Psiquiatria da Infância e da Adolescência. SP, Santos: 1994, pp. 549-555.

BASAGLIA, F. A Psiquiatria Alternativa: contra o Pessimismo da Razão, o Otimismo da Prática. 3ํe. ed. SP: Ed. Brasil Debates 1982, 158p.

BARRETTO, K. D. Ética e Técnica no Acompanhamento Terapêutico: Andanças com Dom Quixote e Sancho Pança. São Paulo: Unimarco, 1998, 210p.

BUSTAMANTE, M. P. de. O Acompanhamento Terapêutico no Cotidiano da Vida: ou Memória da Loucura: e Agora, José? 2003. Disponível em: < http://siteat.cjb.net/ > Acessado em: 30/07/2003.

CABRAL, K. V.; BELLOC, M. M. O Acompanhamento Terapêutico como Dispositivo da Reforma Psiquiátrica: duas Experiências em Saúde Mental Coletiva. In Palombini, A. de L. et al. Acompanhamento Terapêutico na Rede Pública: a Clínica em Movimento. Porto Alegre: Editora da UFRGS, 2004, pp. 113-124.

CAMPBELL, R. J. Dicionário de Psiquiatria. SP: Martins Fontes, 1996, $644 \mathrm{p}$.

CARVALHO, S. S. Acompanhamento Terapêutico: que Clínica É essa? SP: Annablume, 2004, 148p.

CAUCHICK, M. P. Sorrisos Inocentes, Gargalhadas Horripilantes: Intervenções no Acompanhamento Terapêutico. SP: Annablume, 2001,142p.

CHNAIDERMAN, M. Construindo Possibilidades de Clínicas Multifacetadas: Caleidoscópios Cotidianos. In Palombini, A. de L. et al. Acompanhamento Terapêutico na Rede Pública: a Clínica em Movimento. Porto Alegre: Editora da UFRGS, 2004, pp. 13-16.

COIMBRA, C. M. B. Desenvolvimento Sociocultural e Político (6080) e Meios Psicoterápicos. In Ciornai, S. (org.). 25 Anos depois: Gestalt-terapia, Psicodrama e Terapias Neo-reichianas no Brasil. SP: Agora, 1995, 66p.

FERREIRA, G. Panorama sobre a Reforma Psiquiátrica Brasileira no Rio de Janeiro: do Manicômio Público ao Lar Abrigado. In Conselho Federal de Psicologia (org.). Loucura, Ética e Política: Escritos Militantes. SP: Casa do Psicólogo, 2003, pp. 175-180.

GAVIOLI, C.; RANOYA, F.; ABBAMONTE, R. A Prática do Acompanhamento Educacional na Inclusão Escolar: do Acompanhamento do Aluno ao Acompanhamento da Escola. In Colóquio do LEPSI IP/FE-USP: Psicanálise, Infância e Educação, ano 03. São Paulo, out. de 2001. Disponível em: <http:// w w w. p r o c e e d i n g s. s c i e I o.b r/ scielo.php?pid=MSC0000000032001000300020\&scipt=sc_arttext\&tng=pt >. Acessado em: 17/12/2004.

GUATTARI, F. Caosmose: um Novo Paradigma Estético. RJ: Ed. 34, 1992, 203p.

JONES, M. A Comunidade Terapêutica. Petrópolis, RJ: Vozes, 1968.

LEONARDIS, O. de; MAURI, D.; ROTELLI, F. Prevenir a Prevenção. In Rotelli, F.; Leonardis, O. de; Mauri, D.; Risio, C. de. Desinstitucionalização. Org.: Fernanda Nicácio. SP: Hucitec, 1990, pp. 65-87.
MAUER, S. K. de; RESNIZKY, S. Acompanhantes Terapêuticos e Pacientes Psicóticos: Manual Introdutório a uma Estratégia Clínica. SP: Papirus, 1987, 164p.

MORIN, E. Epistemologia da Complexidade. In Schnitman, D. F. (org.). Novos Paradigmas, Cultura e Subjetividade. Porto Alegre: Artes Médicas, 1996, pp. 274-289.

PALOMBINI, A. de L. A Ética nas Micropolíticas de Atenção à Loucura. In Conselho Federal de Psicologia (org.). Loucura, Ética e Política: Escritos Militantes. SP: Casa do Psicólogo, 2003, pp. 159-163.

PALOMBINI, A. de L. et alli. Acompanhamento Terapêutico na Rede Pública: a Clínica em Movimento. Porto Alegre: Editora da UFRGS, 2004, 145p.

PELLICCIOLI, E.; GUARESCHI, N.; BERNARDES, A. O Trabalhador da Saúde Mental na Rede Pública: o Acompanhamento Terapêutico na Rede Pública. 2004. Disponível em: <http:// www.rizoma.ufsc.br/semint/trabalhos/ Eduardo\%20Pelliccioli\%20e\%20Neusa\%20Guareschi\%20\%20PUC\%20RS.doc > Acessado em: 25/06/2004.

PORTO, M.; SERENO, D. Sobre o Acompanhamento Terapêutico. In A CASA, Equipe de Acompanhantes Terapêuticos do Hospital-Dia (org.). A Rua como Espaço Clínico: Acompanhamento Terapêutico. SP: Escuta, 1991, pp. 23-31.

PULICE, G.; ROSSI, G. Acompañamiento Terapéutico: Aproximaciones a su Conceptualización-Presentación de Material Clínico. Buenos Aires: Polemos Editorial, 1997, 161p. REIS NETO, R. de O. Acompanhamento Terapêutico: Emergência e Trajetória Histórica de uma Prática em Saúde Mental no RJ. Pontifícia Universidade Católica do Rio de Janeiro (PUCRJ). Mestrado em Psicologia Clínica, 1995. Orientadora: Esther Arantes de Magalhães.

ROLNIK, Suely. Clínica Nômade. In A CASA, Equipe de Acompanhantes Terapêuticos do Hospital-Dia (org.). A Rua como Espaço Clínico: Acompanhamento Terapêutico. São Paulo: Escuta, 1997, pp. 83-97.

SERENO, D. Acompanhamento Terapêutico e Cinema. In A CASA, Equipe de Acompanhantes Terapêuticos do Hospital-Dia (org.). Crise e Cidade: Acompanhamento Terapêutico. SP: EDUC, 1997, pp. 49-59.

SILVA, A. S. T. da. O Fazer Andarilho: o Acompanhante Terapêutico como um Agente Político. Primeiro Congresso Ibero-americano de Acompanhamento Terapêutico. Faculdade de Medicina, Universidade Nacional de Buenos Aires-Buenos Aires, 2003.

SINDICATO MÉDICO DO RIO GRANDE DO SUL [SIMERS] (2005). Deputado Adilson Troca Assume Projeto de Reforma Psiquiátrica. Porto Alegre/RS. 24 de fevereiro. Disponível em: < http:// www.simers.org.br/deputadoadilson.php >. Acessado em: 25/04/05.

TEIXEIRA, A. P. A.; DENAME, D.; BALDUINO, R. de C. O Acompanhamento Terapêutico e um Enfoque Humanista das Relações Familiares. In A CASA, Equipe de Acompanhantes Terapêuticos do Hospital-Dia (org.). A Rua como Espaço Clínico: Acompanhamento Terapêutico. SP: Escuta, 1991, pp. 167-173.

\section{Referências}

